\title{
RELIABILITY MONITORING OF BROADBAND ACCESS NETWORKS
}

\section{BADANIE NIEZAWODNOŚCI PRACY SZEROKOPASMOWYCH SIECI DOSTEPOWYCH}

\author{
${ }^{1}$ Krzysztof Perlicki, ${ }^{2}$ Mirosław Siergiejczyk, ${ }^{2}$ Marek Stawowy \\ ${ }^{1}$ Politechnika Warszawska, Wydział Elektroniki i Technik Informacyjnych, \\ ${ }^{2}$ Politechnika Warszawska, Wydział Transportu
}

\begin{abstract}
One of the critical issues for broadband accesss is how to test the access network infrastructure and quality of optical signal. The installation and powering up of an optical fiber access networks requires measurement techniques for verifying the link has been configured properly and that its constituent components are functioning correctly. Maintenance functions for a broadband optical access network are classified in two main categories: preventive maintenance and postfault maintenance. The first one consists of: surveillance (to detect degradation in optical fiber components, or any other anomalous condition not preventing the signal transmission,), testing (to measure and locate any detected degradation or anomalous condition) and control (fiber identification and fiber transfer to allow the testing of the link.). In turn second one consisits of: surveillance (to detect alarms or trouble reports and activate a procedure for restoration), testing (to locate the fault and/or verify the carrier performances after the restoration) and remedy (fiber identification, fiber repair or fiber transfer to restore the link).
\end{abstract}

Keywords: optical transmission, fiber optics, access networks monitoring

Streszczenie: Instalacja, uruchomienie i utrzymanie szerokopasmowych optycznych sieci dostępowych wymaga zastosowania technik pomiarowych umożliwiajacych kontrole jakości instalowanych jej elementów skladowych, jakości transmisji danych oraz precyzyjna lokalizacje zaistniatych $w$ taczu światlowodowym uszkodzeń. Zakres czynności zwiazanych z monitorowaniem, a który dotyczy problematyki utrzymania sieci dostępowej, jest tradycyjnie dzielony na dwie grupy. Do pierwszej grupy zaliczamy szereg działan zapobiegawczych, prewencyjnych (preventive maintenance) mające miejsce przed wystapieniem uszkodzenia sieci świattowodowej. Do drugiej grupy zaliczamy szereg działań mających miejsce już po wystapieniu uszkodzenia sieci (post-fault maintenance).

Stowa kluczowe: transmisja optyczna, świattowody, monitorowanie sieci dostepowych 
Reliability monitoring of broadband access networks

Badanie niezawodności pracy szerokopasmowych sieci dostępowych

\section{Wstęp}

Instalacja, uruchomienie i utrzymanie optycznych sieci dostępowych wymaga

zastosowania technik pomiarowych umożliwiających kontrolę jakości instalowanych elementów składowych sieci dostępowej, jakości samej transmisji danych oraz precyzyjną lokalizację zaistniałych w linii światłowodowej uszkodzeń $[1,2]$. Zakres działań związanych $\mathrm{z}$ monitorowaniem, a który dotyczy problematyki utrzymania sieci dostępowej jest tradycyjnie dzielony na dwie grupy. Do pierwszej grupy zaliczamy działania zapobiegawcze, prewencyjne (preventive maintenance) mające miejsce przed wystąpieniem uszkodzenia sieci światłowodowej. Do drugiej grupy zaliczamy działania mające miejsce już po wystąpieniu uszkodzenia sieci (post-fault maintenance) [3]. Dla każdej z wymienionych grup przypisujemy szereg czynności. Do czynności związanych z działaniami zapobiegawczymi zaliczamy: nadzór (detekcja degradacji sieci dostępowej, testowanie (pomiar i lokalizację zmian degradujących sieć dostępową), kontrola (identyfikacja światłowodów w sieci dostępowej. Natomiast do czynności związanych $\mathrm{z}$ działaniami wykonywanymi po wystąpieniu uszkodzenia sieci zaliczamy: nadzór (detekcja alarmów, raportowanie i przywracanie sieci dostępowej do pracy), testowanie (lokalizacja uszkodzeń i weryfikację funkcjonowania sieci dostępowej), kontrola (identyfikacja części składowych sieci dostępowej, które mają być poddany naprawie).

\section{Weryfikacja infrastruktury sieci dostępowej}

Z punktu widzenia poprawnego działania optycznych sieci dostępowych i właściwego funkcjonowania ich systemów zarządzania ważne jest w jaki sposób zbierane są dane $\mathrm{z}$ systemu badającego czyli monitorującego pracę sieci dostępowej. Możemy wyróżnić dwa podejścia, uwzględniające lokalizację urządzeń pomiarowych systemu monitorowania sieci dostępowej. Pierwsze z nich to rozwiązanie rozproszone czyli zdecentralizowane, a drugie określa się mianem rozwiązania scentralizowanego. W przypadku rozwiązania rozproszonego pomiar wybranych parametrów sieci dostępowej odbywa się w obrębie jednostki ONU (Optical Network Unit) lub w ściśle określonych, wybranych lokalizacjach sieci światłowodowej. To rozwiązanie jest kosztowne i wymaga łączności, służącej do przekazu danych pomiarowych, między urządzeniami pomiarowymi systemu monitorowania i systemem utrzymania. Innym rozwiązaniem należącym do tej kategorii jest ręczne wykonywanie okresowych pomiarów przez służby techniczne. Jak się można domyślać to rozwiązanie jest kosztowne i przede wszystkim czasochłonne. W przypadku rozwiązania zcentralizowanego urządzenie pomiarowe systemu monitorowania jest umieszczone po stronie centralowej czyli od strony jednostki OLT (Optical Line Terminal). Monitorowanie sieci dostępowej, służące sprawdzeniu jakości działania tej sieci na najniższym fizycznym poziomie, można sprowadzić do pomiaru jakości transmitowanego sygnału optycznego i pomiaru jakości fizycznej infrastruktury. 
W przypadku pomiaru jakości sygnału optycznego transmitowanego przez sieć dostępową $\mathrm{z}$ powodzeniem można zastosować tradycyjne metody pomiaru z wykorzystaniem miernika długości fali lub analizatora widma optycznego. Do podstawowych parametrów sygnału optycznego, które należy mierzyć zaliczamy: szczytową moc optyczną wyznaczaną na środkowej długości fali sygnału optycznego, położenie sygnału w widmie optycznym i optyczny stosunek sygnału do szumu. Ten ostatni parametr ma znaczenie w odniesieniu do sieci dostępowych wykorzystujących wzmacniacze optyczne. Ocenę infrastruktury światłowodowej sieci dostępowej można wykonać poprzez pomiar tak zwanej ciągłości sieci światłowodowej. W najprostszym przypadku sprowadza się on do określenia poziomu mocy optycznej sygnału transmitowanego pomiędzy daną jednostką ONU a jednostką OLT [4]. Zmiana mocy optycznej w danej szczelnie czasowej (w przypadku systemów dostępowych bazujących na technice Time Division Multiplexing) lub na danej długości fali (w przypadku systemów dostępowych bazujących na technice Wavelength Division Multiplexing) wskazuje na fizyczną degradację połączenia. W skrajnym przypadku brak sygnału wskazuje na uszkodzenie jednostki ONU lub przerwanie linii światłowodowej. Bolączką takich metod jest niemożność precyzyjnego zlokalizowania miejsca uszkodzenia infrastruktury światłowodowej. Do tego celu należy zastosować metodę reflektometrii światłowodowej. Pomiary wykorzystujące reflektometrię światłowodową pozwalają na uzyskanie, poza precyzyjnym pomiarem długości linii światłowodowej, dokładnej informacji o lokalizacji i parametrach (tłumienie i reflektancja) zdarzeń występujących w linii światłowodowej. Dodatkową zaletą tej metody pomiarowej jest to, że wymaga ona dostępu tylko do jednego końca światłowodu. Należy również zwrócić uwagę na długość fali przy której wykonywany jest pomiar reflektometryczny. W systemach dostępowych typu BPON, EPON, GPON, NG-PON1 czy też NG-PON2 do celów związanych z realizacją konkretnych usług czyli mówiąc inaczej do realizacji transmisji danych $\mathrm{w}$ kierunku downstream i upstream wykorzystuje się zakres długości fali od $1260 \mathrm{~nm}$ do $1600 \mathrm{~nm}$. W związku z tym do celów metrologicznych należy zastosować tzw. pasmo U obejmujące długości fali od $1625 \mathrm{~nm}$ do $1675 \mathrm{~nm}$. Pozwala to na zastosowania trybu monitorowania typu in-service (czyli monitorowania podczas pracy systemu dostępowego) bez niebezpieczeństwa zakłócenia samej transmisji danych. Technika reflektometryczna wykorzystująca te długości fali nosi nazwę reflektometrii pozapasmowej. Jest on rekomendowania w zaleceniach ITU-T L. 41 [5] i L. 66 [6]. Warto wspomnieć, że do samej identyfikacja pojedynczego światłowodu w kablu światłowodowym sieci dostępowej możemy się posłużyć metodą podaną w zaleceniu ITU-T L. 85 [7] czyli metodę makrozgięciową, Metoda tego typu pomiaru polega zgięciu światłowodu tak by nastąpił nieznaczny wyciek części sygnału optycznego. Następnie sygnał ten jest odbierany za pomocą fotoodbiornika. Sygnał testowy wprowadzony do światłowodu powinien być modulowany sygnałem sinusoidalnym z częstotliwością typowo $270 \mathrm{~Hz}, 1 \mathrm{kHz}$ lub $2 \mathrm{kHz}$. 
Reliability monitoring of broadband access networks

Badanie niezawodności pracy szerokopasmowych sieci dostępowych

W tej metodzie powinno się stosować długość fali z pasma U. Właściwie wykonany pomiar za pomocą tej metody nie powoduje uszkodzenia samego włókna i nie powoduje zakłócenia transmisji danych, która odbywa się w analizowanym światłowodzie. Pomiar reflektometryczny pozapasmowy pozwala na identyfikację i lokalizację wszelkich uszkodzeń niejako z wyprzedzeniem. Wyprzedzeniem rozumianym jako detekcję uszkodzenia, które dla długości fali stosowanych systemach dostępowych z punktu widzenia jakości ich pracy jest jeszcze nieodczuwalne. Wynika to faktu, że pomiar reflektometryczny jest tym czulszy im jest wykonywany na większej długości fali. Okazuje się, że możemy na echogramie uzyskanym z pomiaru reflektometrycznego wykonanego przy długości fali $1625 \mathrm{~nm}$ zaobserwować degradację linii światłowodowej (spowodowaną zgięciem światłowodu), a przy pomiarze na długości fali $1550 \mathrm{~nm}$ żadnych zmian nie zaobserwujemy. Zmiany te mogą być widoczne dla tego drugiego pomiaru dopiero po pewnym czasie gdy degradacja linii światłowodowej będzie większa. Monitorowanie infrastruktury światłowodowej sieci dostępowej z wykorzystaniem reflektometru światłowodowego w swej klasycznej wersji jest wysoko nieefektywny. Wynika to $\mathrm{z}$ samej budowy analizowanej struktury sieciowej w przeważającej mierze opartej o architekturę punkt-wielepunktów. Przede wszystkim trzeba zwrócić uwagę na to, że sygnał rozproszony docierający do reflektometru pochodzi z wielu ramion sieci dostępowych czyli z wielu odcinków światłowodów dystrybucyjnych. Powoduje to nakładanie się sygnałów i maskowanie zdarzeń detekowanych przez reflektometr. Poza tym $\mathrm{w}$ sieci dostępowej opartych na zwielokrotnieniu czasowym, czyli wszystkich z wyłączeniem NG-PON2, następuje podział mocowy sygnału. Po podziale rozpraszany sygnał jest silnie zredukowany mocowo. Na przykład przy podziale 1do 8 następuje spadek mocy rozdzielonych sygnałów optycznych o $9 \mathrm{~dB}$, a przy podziale 1 do 32 o $15 \mathrm{~dB}$. Efektem tego jest bardzo niski poziom sygnału rozproszonego docierającego do odbiornika $\mathrm{w}$ reflektometrze (z każdego punktu w linii światłowodowej rozpraszanych wstecznie jest tylko 0,0001 część energii przesyłanego sygnału), powodując silne zredukowanie zasięgu pomiaru. Poza tym przy standardowych ustawieniach reflektometru spadek poziomu sygnału o 5-7 dB interpretowany jest jako koniec analizowanego światłowodu.

\section{Pomiary reflektometryczne w sieciach dostępowych}

$\mathrm{W}$ celu skorzystanie z zalet pomiaru reflektometrycznego przy diagnostyce sieci dostępowych należy przeprowadzić pewne modyfikacje tej techniki pomiarowej. Jedno $\mathrm{z}$ prostszych rozwiązań bazuje na pomyśle zróżnicowania długości odcinków światłowodu dystrybucyjnego. Rozwiązanie to wymaga dokładnego doboru długości odcinków światłowodu dystrybucyjnego tak by piki odbicia fresnelowskiego, wskazujące na koniec światłowodów dystrybucyjnych, były zlokalizowane w różnych miejscach echogramu. Każdy pik jest jednoznacznie powiązany $z$ daną jednostką ONU. W przypadku zniknięcia $z$ echogramu danego piku jesteśmy w stanie określić z jaką jednostką ONU nie ma połączenia. 
Przy jakichkolwiek modyfikacjach długości światłowodów dystrybucyjnych wymagana jest aktualizacja przypisania danego piku odbicia fresnelowskiego $\mathrm{z}$ echogramu do konkretnej jednostki ONU. W tej metodzie najwygodniej jest zastosować pomiaru pozapasmowy np. na długości $1625 \mathrm{~nm}$. Na wejściu ONU i OLT umieszcza się filtr optyczny wycinający długość fali stosowanej w pomiarze i przepuszczany jest tylko sygnał transmisji danych. Natomiast na wejście elementu odbiciowego i wejście reflektometru wydzielany jest sygnał o długości fali $1625 \mathrm{~nm}$ przez filtr optyczny. Następuje w ten sposób rozdzielenie sygnału pomiarowego i sygnału transmisji danych. (rys. 1).

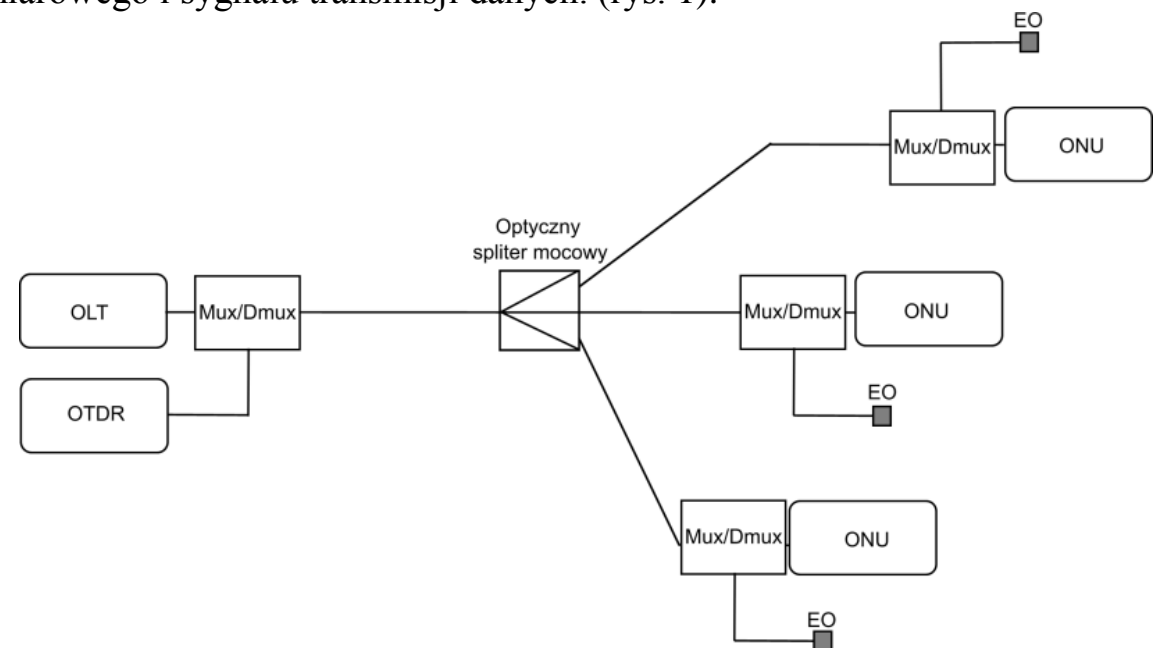

Rys. 1 Pomiar reflektometryczny z wykorzystaniem rożnych dtugości świattowodów dystrybucyjnych; OLT - Optical Line Terminal, ONU - Optical Network Unit, OTDR - Optical Time Domain Reflectometry, EO - Element Odbiciowy, Mux/Dmux - Multiplekser/Demutiplekser

Odmianą przedstawionego rozwiązania jest wykorzystanie przełączalnego elementu odbiciowego. W tym rozwiązaniu stosujemy podobny układ pomiarowy z tym, że sygnał z reflektometru po stronie ONU jest kierowany nie bezpośrednio do elementu odbiciowego ale na przełącznik optyczny. Przełącznik optyczny jest zdalnie sterowny przez system utrzymaniowy sieci dostępowej. W przełączniku optycznym sygnał jest przełączany do elementu bezodbiciowego lub odbiciowego. $\mathrm{W}$ ten sposób możemy wybierać z którym ONU sprawdzana jest ciągłość połączenia [4]. Jednostki ONU można również wyróżnić na echogramie poprzez zastosowanie po stronie ONU specjalnie dobranych odbiciowych selektywnych falowo elementów; zwykle są to odbiciowe siatki braggowskie. Siatki braggowskie dobiera się tak by długość fali odbitej od strony każdej z jednostek ONU była inna. Tak więc połączenia z poszczególnymi jednostkami ONU jest identyfikowane w oparciu o długość fali odbitej od selektywno falowo elementu odbiciowego. To rozwiązanie wymaga zastosowania układu pomiarowego z przestrajalnym źródłem światła czyli reflektometru światłowodowego z przestrajalnym źródłem światła. 
Reliability monitoring of broadband access networks

Badanie niezawodności pracy szerokopasmowych sieci dostępowych

Schemat takiego układu z kombinacją dwóch różnych siatek braggowsskich pokazano na rys. 2 .

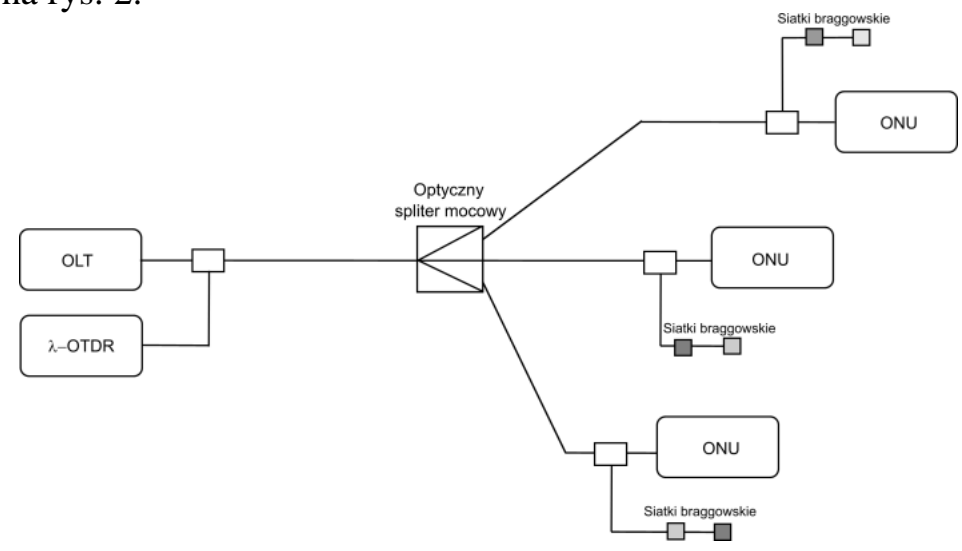

Rys. 2 System monitorowania z wykorzystaniem reflektometru światlowodowego i odbiciowej sitaki braggowskiej; OLT - Optical Line Terminal, ONU - Optical Network Unit, $\lambda$-OTDR - Optical Time Domain Reflectometry (wersja przestrajalny)

W przypadku gdy wykorzystujemy pary połączonych ze sobą selektywno falowych elementów odbiciowych (siatek braggowskich), każdy z elementów tej pary odbija inną długość fali [8]. Po stronie OLT umieszczono przestrajalny reflektometr światłowodowy Na rys. 3 przedstawia wyniki pomiaru reflektometrycznego.
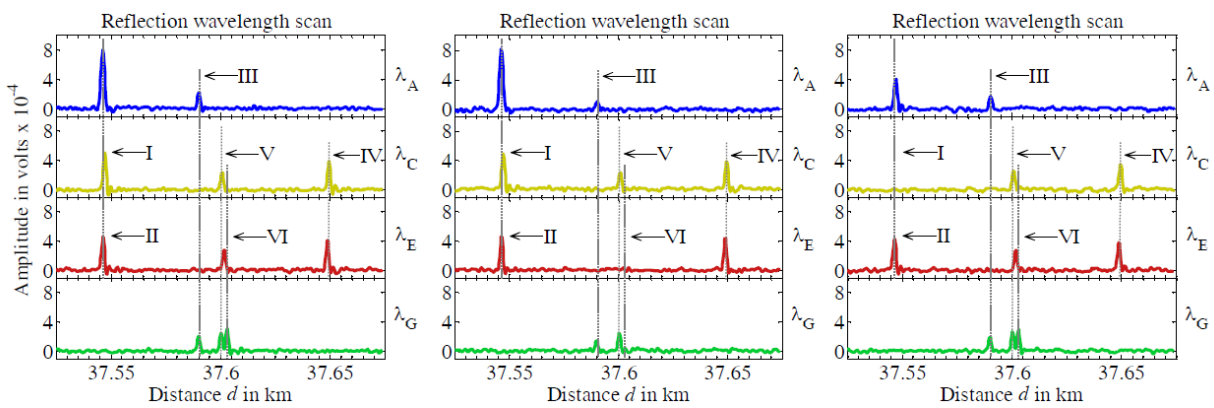

Rys. 3 Wyniki pomiaru reflektometrycznego wykorzystującego przestrajalny reflektometr światlowodowy i pary siatek braggowskich [8]

Do pomiaru stosowane są cztery długości fali 1597,18 nm, 1598,89 nm, 1600,60 $\mathrm{nm}$ i $1602,31 \mathrm{~nm}$. Dane zakończenie identyfikowane jest na podstawie pary odbić zachodzących na różnych długościach fali. Zakończenie I jest identyfikowane na podstawie piku odbicia na długości fali $1597,18 \mathrm{~nm}$ i 1598,89 nm, zakończenie II na podstawie odbicia na długości fali 1600,60 nm i 1597,18 nm, zakończenie III na podstawie odbicia na długości fali $1602,31 \mathrm{~nm}$ i $1597,18 \mathrm{~nm}$, zakończenie IV na podstawie odbicia na długości fali 1600,60 nm i 1598,89 nm, zakończenie V na podstawie odbicia na długości fali $1602,31 \mathrm{~nm}$ i $1598,89 \mathrm{~nm}$, natomiast zakończenie VI na podstawie odbicia na długości fali 1600,60 nm i 1602,31 nm. 
$\mathrm{Na}$ rys. pokazano sytuacje braku sygnału odbiciowego od zakończenia VI, co wskazuje na utratę połączenia między OLT i ONU skojarzonego z zakończeniem VI. Można sobie również wyobrazić zastosowanie w tym rozwiązaniu źródła szerokopasmowego w części nadawczej reflektometru i analizatora widma (miernika długości fali) $\mathrm{w}$ jego części odbiorcze. Ale jest to rozwiązanie zdecydowanie bardziej złożone $\mathrm{i}$ droższe niż to wykorzystujące przestrajalne źródło światła. Powyższe rozwiązania reflektometryczne umożliwiają określenie, które połączenie między jednostką OLT i ONU jest uszkodzone; czyli z którą jednostką ONU nie ma połączenia. Daje pełen obraz jakości łącza transportowego (od jednostki OLT do pierwszego elementu rozdzielającego). Jednakże te metody nie są $\mathrm{W}$ stanie zdiagnozować jakości poszczególnych łączy dystrybucyjnych. Mówiąc inaczej nie można otrzymać echogramów fizycznych połączeń jednostki OLT $\mathrm{z}$ poszczególnymi jednostkami ONU. Wynika to $\mathrm{z}$ faktu, że sygnał $\mathrm{z}$ reflektometru propaguje się $\mathrm{w}$ każdym $\mathrm{z}$ łączy dystrybucyjnych i pochodzące $\mathrm{z}$ nich sygnały rozproszone nakładają się na siebie. Problem uzyskania echogramu z poszczególnych łączy dystrybucyjnych można rozwiązać przez zastosowanie reflektometru wbudowanego w poszczególne jednostki ONU. Jest to rozwiązanie drogie; wymagające umieszczenia w jednostkach ONU w pełni funkcjonalnych reflektometrów światłowodowych. Pewne obniżenie kosztów można uzyskać poprzez zastosowanie do pomiaru jednego, tzw. centralnego źródła światła (może być zlokalizowane w OLT lub w pobliżu jednostek ONU). Kolejnym rozwiązaniem jest zastosowanie techniki przełączania ścieżki pomiarowej. Przed pierwszym elementem rozdzielającym sygnał transmitowany w kierunku jednostek ONU następuje wydzielenie sygnału pomiarowego wykorzystywanego $\mathrm{w}$ reflektometrze. Jest on kierowany do przełącznika optycznego, sterowanego sygnałem pochodzącym $\mathrm{z}$ systemu utrzymania sieci dostępowej. Wyjścia przełącznika optycznego połączone z poszczególnymi odcinkami światłowodów dystrybucyjnych (rys. 4).

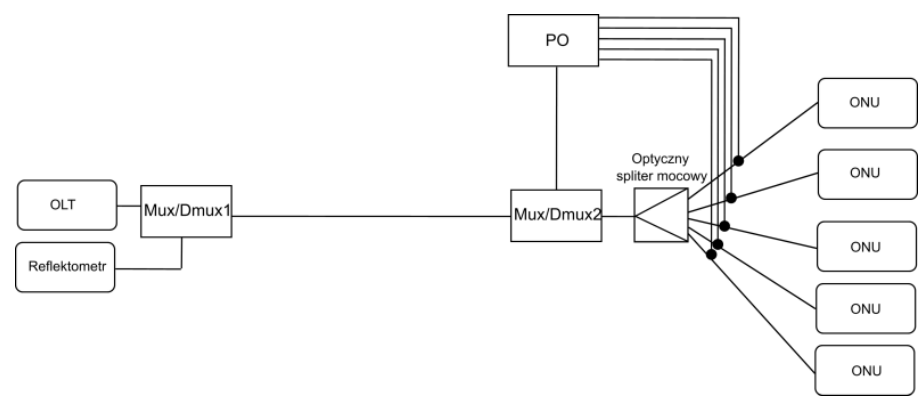

Rys. 4 Układ monitorowania z wykorzystaniem techniki przełaczania ścieżki pomiarowej

Pomiar wykonywany jest na długości fali $\mathrm{z}$ zakresu pasma U. Multiplekser/demultiplekser (MUX/DMUX1 i MUX/DMUX2) rozdziela sygnał związany z transmisją danych i wykorzystywany w pomiarze reflektometryczny. 
Reliability monitoring of broadband access networks

Badanie niezawodności pracy szerokopasmowych sieci dostępowych

Przełącznik PO kieruje sygnał pomiarowy do poszczególnych łączy dystrybucyjnych. Przy pomiarach reflektometrycznych sieci dostępowych podstawowym ograniczeniem jest poziom sygnału docierający do odbiornika reflektometru. Jak już wyżej wspomniano wraz ze wzrostem stopnia podziału następuje gwałtownym spadek mocy sygnału przenoszonego w poszczególnych łączach sieci dostępowej. Rozwiązaniem tego problemu jest zastosowanie wzmacniacza Ramana. Jego zastosowanie zdecydowanie poprawia dynamikę pomiarów reflektometrycznych. Wymagany poziom mocy optycznej pochodzący z pompy optycznej niezbędny do uzyskania wzmocnienia ramanowskiego przekracza $500 \mathrm{~mW}$ w przypadku klasycznych światłowodów telekomunikacyjnych. To jest zasadnicza wada tego rozwiązania. Poza tym kluczową sprawą jest dobór długości fali pompy i długości fali wzmacnianej, która jest wykorzystana do celów metrologicznych. Nie mogą one nachodzić na długości fali stosowane do transmisji danych. Poprawę dynamiki pomiaru reflektometrycznego pokazuje rys. 5 .

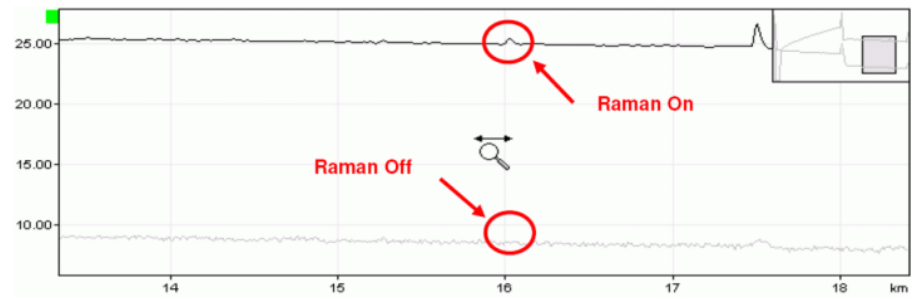

\section{Rys. 5 Poprawa dynamiki pomiaru reflektometrycznego przy zastosowaniu} wzmacniacza Ramana [9]

W rozwiązanie opartym na zastosowaniu wzmocnienia Ramana można zastosować selektywno falowe elementy odbiciowe. Na przykład można wyobrazić sobie rozwiązanie wykorzystujące długość fali pompy Ramana $1450 \mathrm{~nm}$ i długość fali stosowanej do pomiaru reflektometrycznego z zakresu $1550 \mathrm{~nm}$. Największa wartość wzmocnienia Ramanowskiego ma miejsce na fali o długości około $100 \mathrm{~nm}$ większej do długości fali pompy. Oczywiście tego typu pomiar ze względu na wykorzystywane długości fali może być stosowany przez włączeniem sieci do eksploatacji. W przypadku klasycznej reflektometri światłowodowej do analizy wykorzystuje się sygnał pochodzący z rozpraszania Rayleigha zachodzącego na tej samej długości fali co sygnał wprowadzany do światłowodu. Zupełnie inne możliwości metrologiczne oferuje analiza sygnału pochodzącego z nieelastycznego rozpraszania Ramana i Brillouina. W [10] zaproponowano wykorzystanie reflektometrii Brillouina do diagnostyki sieci dostępowej. Kluczem do poprawnej pracy tego układu pomiarowego jest uzyskiwanie z poszczególnych światłowodów dystrybucyjnych sygnałów powstałych z rozpraszania Brillouina o innej długości fali (innej częstotliwości). Jest to trudne, wymaga bowiem starannego doboru światłowodów, pod kątem składu chemicznego, na poszczególne odcinki dystrybucyjne; w praktyce rzecz mało realna. 
W [10] do różnicowania światłowodów dystrybucyjnych zastosowano kontrolowane zróżnicowane naprężenia mechaniczne, które wywołują zróżnicowanie w częstotliwości produktu rozpraszania Brillouina. Natomiast wykorzystanie reflektometrii ramanowskej umożliwia równocześnie klasyczny pomiar reflektometryczny i pomiar rozkładu temperatury - wielkości fizycznej mierzonej reflektometrem ramanowskim i będącej jednym $\mathrm{z}$ kluczowych monitorowanych środowiskowych parametrów infrastruktury telekomunikacyjnej.

\section{Podsumowanie}

Poprawna eksploatacja światłowodowych sieci dostępowych wymaga efektywnego systemu jej monitorowania. System monitorowania powinien spełniać szereg wymogów. System monitorowania powinien być scentralizowany. Zbieranie danych pomiarowych powinno odbywać się po stronie jednostki OLT, tak by można było prosto przekazywać dane pomiarowe $\mathrm{z}$ systemu monitoringu do systemu utrzymania siecią dostępową. Rodzaj stosowanej techniki monitoringu powinien uwzględniać budowę i zasadę działania monitorowanej sieci dostępowej. Pomiar powinien być wykonywany automatycznie. Takie rozwiązanie umożliwia obniżenie kosztów typu OPEX. System monitorowania powinien charakteryzować się skalowalnością. Należy zadbać o zachowanie transparentności pracy systemu monitorowania względem zasobów wykorzystywanych do transmisji danych. Podstawową funkcją monitoringu jest detekcja wystąpienia w sieci dostępowej uszkodzenia. Ponadto system monitorowania powinien umożliwić lokalizację wystąpienia uszkodzenia. Taka funkcjonalność obniża koszty typu OPEX. Koszt wybudowania i utrzymania systemu monitorowania powinny być jak najniższy. System monitorowania powinien być niezawodny co jest rozumiane jako zdolności do realizacji wymaganych funkcji $w$ założonym okresie czasu. System monitorowania musi być niezależny od rodzaju klienta obsługiwanego przez sieć dostępową oraz wykorzystywanego przez niego protokołu komunikacyjnego. Ponadto, czas jaki upłynie między wystąpieniem uszkodzenia w sieci a jego detekcją i przekazaniem do systemu utrzymana powinien być jak najkrótszy.

\section{Literatura}

[1] K. Perlicki K.: Najnowsza generacja optycznych systemów dostępowych, Przegląd Telekomunikacyjny i Wiadomości Telekomunikacyjne, 2-3/2105, 35-40, 2015.

[2] Perlicki K., Siuzdak J.: Dispersion Supported Transmission with a Binary Optical Signal at the Receiver. Optical and Quantum Electronics, 3/1999, 243-247.

[3] Ab-Rahman M. S., N. B. Chuan N. B.: The Overview of Fiber Fault Localization Technology in TDM-PON Network, IEEE International Conference on Electronic Design, Penang, Malaysia, 2008.

[4] Esmail M. A., Fathallah H.: Physical Layer Monitoring Techniques for TDM-Passive Optical Networks: A Survey, IEEE Communications Surveys \& Tutorials, 2/2013, 943-958. 
Reliability monitoring of broadband access networks

Badanie niezawodności pracy szerokopasmowych sieci dostępowych

[5] ITU-T L. 41: Maintenance wavelength on fibres carrying signals, Genewa, 2000.

[6] ITU-T L. 66: Optical fibre cable maintenance criteria for in-service fibre testing in access networks, Genewa, 2007.

[7] ITU-T L. 85: Optical fibre identification for the maintenance of optical access networks, Genewa, 2010.

[8] Bentz C. M., Fritzsche D.: Field Trial of a Novel FTTH/PON Monitoring Technique Based on Unique Wavelength-Selective Mirror Combinations, NM2I.1, National Fiber Optic Engineers Conference, Anaheim, Stany Zjednoczone, 2013.

[9] Yuksel K., Grillet A.: Centralised Optical Monitoring of Tree-structured Passive Optical Networks using a Raman-assisted OTDR, International Conference on Transparent Optical Networks, Rzym, Włochy, 2007.

[10] Takahashi H., Toge K.: Individual PON Monitoring Using Maintenance Band Pulsed Pump-Probe Brillouin Analysis, 18th OptoElectronics and Communications Conference held jointly with 2013 International Conference on Photonics in Switching, Kioto, Japonia, 2013

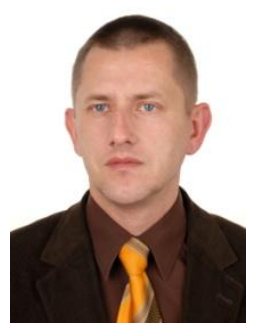

Dr hab. inz. Krzysztof Perlicki, profesor nadzwyczajny Politechniki Warszawskiej. Pracuje w Instytucie Telekomunikacji na Wydziale Elektroniki $i$ Technik Informacyjnych. Do jego głównych zainteresowań zawodowych należy zaliczyć: telekomunikacje, inteligentne sieci elektroenergetyczne, niezawodność $i$ jakości ustug. Jest autorem blisko stu anglojęzycznych i polskojęzycznych publikacji i czterech ksiązek naukowo-technicznych (Udziat 60\%).

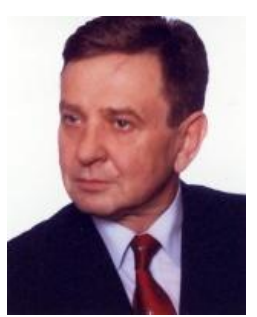

Prof. nadzw. dr hab. inz. Miroslaw Siergiejczyk zainteresowania naukowe wspótautora referatu obejmuja między innymi problemy architektury $i$ ustug systemów $i$ sieci telekomunikacyjnych ze szczególnym uwzględnieniem możliwości $i c h$ wykorzystania $w$ transporcie, niezawodności i eksploatacji systemów $i$ sieci teleinformatycznych, modelowanie, projektowanie i organizacja sieci i systemów teleinformatycznych $w$ transporcie (Udziat 30\%).

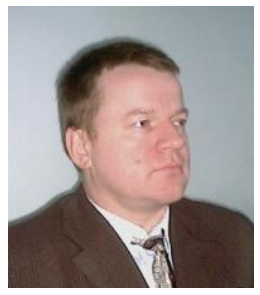

Dr inz. Marek Stawowy - Adiunkt wydziatu Transportu Politechniki Warszawskiej. Zainteresowania naukowe: komputerowa analiza obrazów, jakość informacji, modelowanie niepewności jakości informacji. Autor kilkudziesięciu artykutów naukowo-technicznych (Udziat 10\%). 